\title{
Choledochoduodenal fistula complicating chronic duodenal ulcer in Nigerians
}

\author{
E. A. LEWIS AND S. P. BOHRER \\ From the Departments of Medicine and Radiology, University of Ibadan, Nigeria
}

Peptic ulceration was thought to be rare in Nigerians until the 1930s when Aitken (1933) and Rose (1935) reported on this condition. Chronic duodenal ulcers, in particular, are being reported with increasing frequency (Ellis, 1948; Konstam, 1959). The symptoms and complications of duodenal ulcers in Nigerians are the same as elsewhere, but the relative incidence of these complications differs markedly. Pyloric stenosis is the commonest complication followed by haematemesis and malaena in that order (Antia and Solanke, 1967; Solanke and Lewis, 1968). Perforation though present is not very common.

A remarkable complication found in some of our patients with duodenal ulcer who present themselves for radiological examination is the formation of a fistulous communication between the duodenum and the biliary system. This finding has prompted evaluation of these cases in order to compare them with reports of similar findings in the American and the European literature.

\section{METHOD}

A review of the records at University College Hospital, Ibadan, Nigeria, from 1960 to 1967 revealed 13 cases of proven biliary-digestive fistulas. Twelve of the cases were proven at surgery as well as radiologically. The one patient who did not come to surgery showed air in the biliary tree on plain abdominal radiographs and reflux of barium from the duodenal cap into the bile ducts during barium meal examination.

\section{RESULTS}

The 13 cases over a period of seven years may be analysed as follows:

AGE All of the patients were over the age of 30 except for one case in a boy of 18 .

SEX There were 11 male patients and two females, a ratio of $5 \cdot 5: 1$.
SOCIAL CLASS All the patients were in the lower socio-economic class. This fact may only reflect the patients seen at University College Hospital.

AETIOLOGY Twelve $(92.3 \%)$ of the fistulas resulted from chronic duodenal ulcer and in only one case from gall bladder disease.

CLINICAL FEATURES There were no special symptoms or signs for this complication. All patients except the one with gall bladder disease presented with symptoms of chronic duodenal ulcer or with those of pyloric stenosis of which there were four cases. In the case with gall bladder disease the history was short and characterized by fever, right-sided abdominal pain, jaundice, and dark urine.

Symptoms of dyspepsia occurred for over three years in all patients except two who had had symptoms for less than a year; the longest duration was 20 years. The one patient with gall bladder disease presented with two days' history.

DETECTION OF COMPLICATION All cases resulting from chronic duodenal ulcer were first discovered during radiological examination. There were seven cases with gas in the hepatic and common bile ducts (Fig. 2) and in all but two cases barium refluxed into the common bile duct and/or hepatic ducts at barium meal examination (Fig. 1). Both of these fistulas were proven at surgery. One was the patient with gall bladder disease in whom gas was seen in the wall of the gall bladder and in the hepatic ducts.

SITE OF ULCER In all patients with chronic duodenal ulcer the superior aspect of the first portion of the duodenum was involved; the anterosuperior aspect in nine cases and the retrosuperior aspect in two cases.

In all cases there were extensive adhesions and fibrosis; these involved the ligaments, mesentery, duodenum, common bile ducts, gall bladder, colon, and sometimes the liver.

BLOOD GROUP Eleven of the 12 patients with duo- 
denal ulcer belonged to the blood group $\mathrm{O}$. The other patient was in group A. Fifty-two per cent of the normal population in the western state of Nigeria belong to group $\mathrm{O}$ and $22 \%$ to group $\mathrm{A}$.

\section{ILLUSTRATIVE CASES}

CASE 1 O.A. (HOSPITAL No. 6227) This 18-year-old student was seen at the University College Hospital, Ibadan, with a five-year history of recurrent episodes of epigastric pain. Four weeks after admission he began to vomit after meals and lost weight rather fast.

On examination, he was found to be thin and very dehydrated. Abdominal examination showed marked tenderness in the epigastrium and a succussion splash was elicited. Peristalsis was also visible.

On barium meal examination there was a perforating ulcer in the first part of the duodenum and barium entered the proximal portion of the common bile duct and hepatic ducts (Fig. 1).

At operation there were gross adhesions around the pylorus and first part of the duodenum. There was an anterosuperior ulcer crater in the first part of the duodenum.

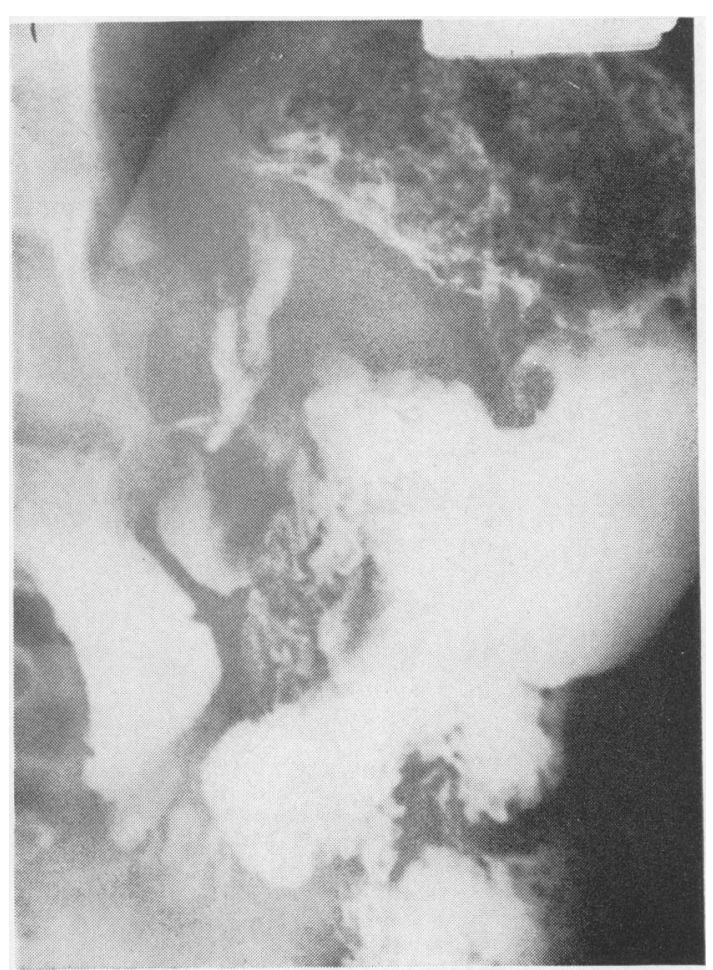

FIG. 1.
CASE 2 S.I. (hOSPITAL No. 139926) This 37-year-old barber presented with a history of upper abdominal pain for 15 years, at first periodic but a few months before admission the pain had become constant and was made worse by food and relieved by vomiting.

On examination he was a thin and dehydrated man with deep para-umbilical tenderness. He had a succussion splash and peristalsis was visible.

At barium meal examination, a considerable degree of pyloric obstruction was present and the duodenal cap was deformed. The appearance was consistent with a chronic duodenal ulcer. Gas was present in the biliary tree.

At operation there was an anterosuperior duodenal ulcer with scarring and adhesions of the gastro-hepatic ligament and gall bladder.

CASE 3 A.T. HOSPITAL No. 67652). A 35-year-old Yoruba housewife was admitted with a two-week history of febrile illness with rigors, vomiting, and generalized aches and pain. She had had epigastric pain for over three years.

On examination she was febrile and slightly jaundiced. She had some tenderness in the epigastrium and hepato-

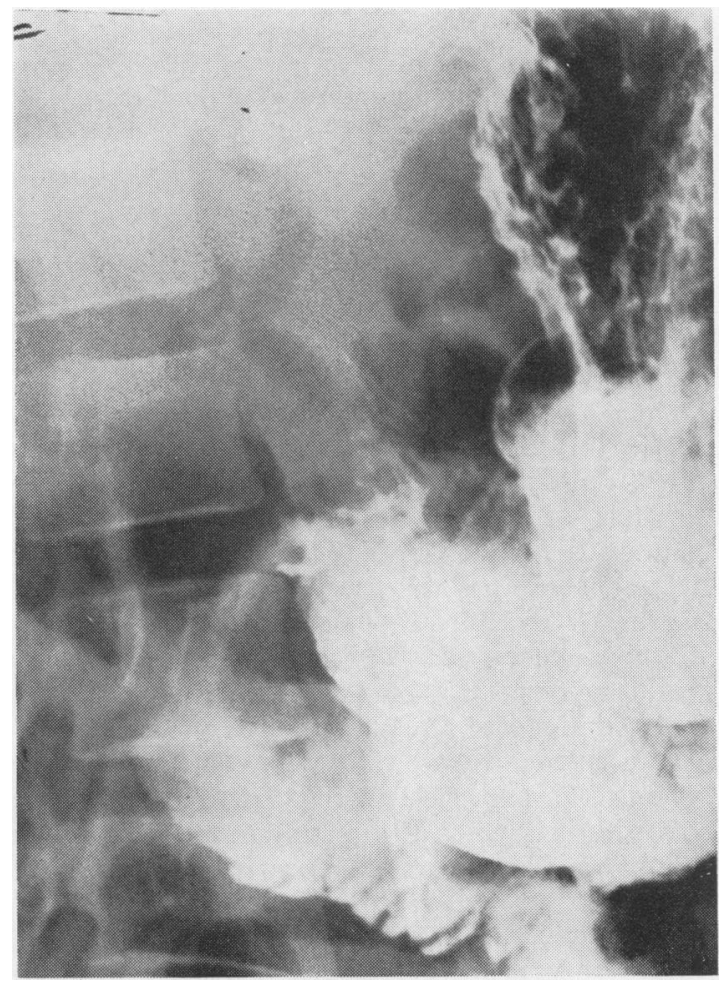

FIG. 2 .

in the distal portion of the common bile duct.

FIG. 2. Gas is seen in the biliary ducts above the duodenal bulb. 
splenic enlargement. While in hospital she had several episodes of massive haematemesis for which she received a total of 14 pints of blood.

A barium swallow showed no evidence of varices. At barium meal examination barium entered the common bile duct but no ulcer crater was demonstrated with certainty.

At operation there was an ulcer in the first part of the duodenum penetrating into the common bile duct. The common bile duct was enormously dilated above the level of the perforation. The duct below this level appeared normal. The liver was enlarged with abscesses in its substance and in relation to the diaphragmatic surface of the left lobe. There was no evidence of cirrhosis.

CASE 4 Y.A. (hOSPITAL No. 147798) This 43-year-old housewife was admitted to University College Hospital with a two-day history of vomiting, fever, abdominal swelling, and pain. She had noticed the swelling three months before and it had slowly been increasing in size.

On examination she was febrile, not jaundiced, but had a tender mass in the right hypochondrium.

Radiographs of the abdomen showed gas in the wall of the gall bladder and in the hepatic ducts.

At operation, a cholecystogastric fistula was found with adhesions to the transverse colon and omentum. The whole mass was adherent to the anterior abdominal wall.

On microscopic examination the gall bladder showed acute inflammatory reaction in the wall and there was a fibrino-haemorrhagic peritonitis in keeping with acute cholecystitis with peritonitis.

\section{DISCUSSION}

A number of papers have been written recently by American and European authors (Cogbill and Roth, 1953; Dean, 1939; Kehr, 1913; Pitman and Davies, 1963; Waggoner and Le Mone, 1949; Epperson and Walters, 1953; Monaco, Brunetti, and Cocchieri, 1966) on fistulous communications between the digestive and biliary tracts. In their reports gall bladder disease accounts for $90 \%$ of these fistulas. In our series of 13 cases, choledochoduodenal fistulas account for all but one case and are due to chronic duodenal ulcer disease. There was one fistula produced from gall bladder disease due to acute cholecystitis (case 4).

Gall bladder disease cannot be said not to exist in Nigeria (Parnis, 1964) but relative to European countries it is much less readily found. The reason for this geographical difference has not been elucidated; it may be related to diet.

There have been isolated case reports of choledochoduodenal fistula dating back to those of Stephenson (1921), Garland and Brown (1942), and Weinberger and Rosenthal (1945). Craighead and St. Raymond (1954) reported four cases while the largest collection of five cases with a review of the literature was by Hutchings, Wheeler, and Puestow (1956). Our analysis of 12 cases over a period of seven years may possibly now be the largest series.

In our series all the patients were over the age of 30 except for a boy of 18 . The oldest patient was 60 years old. In the review of 28 cases from the world literature (Hutchings et al, 1956), the average age was 45 years, the youngest being 24 years and the oldest 85 years.

The duration of peptic ulcer history averaged $11 \cdot 1$ years in their series while in ours it is $7 \cdot 2$ years. It is pertinent to add that estimating age in our patients is often very arbitrary and this applies to the duration of symptoms also. It may be reasonable to assume that symptoms existed longer than actually recorded.

There is agreement that choledochoduodenal fistula occurs mostly in men. We had only one case in a woman in our series. There were none in the review by Hutchings et al (1956).

In our series this complication was associated in all cases with gross scarring and adhesions around the ulcer. The ligaments, mesentery, common bile duct, the gall bladder, duodenum, and occasionally the transverse colon were all involved in the cicatrical process. Four of our cases had associated duodenal stenosis, the most common complication of duodenal ulcer in Ibadan. There was one case of associated duodenal stenosis in the series of Hutchings et al (1956).

The site of the ulcers was superiorly in the first portion of the duodenum in all cases, in the antero-superior aspect in most of the cases, and in the retrosuperior aspect in two cases. Normally the common bile duct runs behind the superior aspect

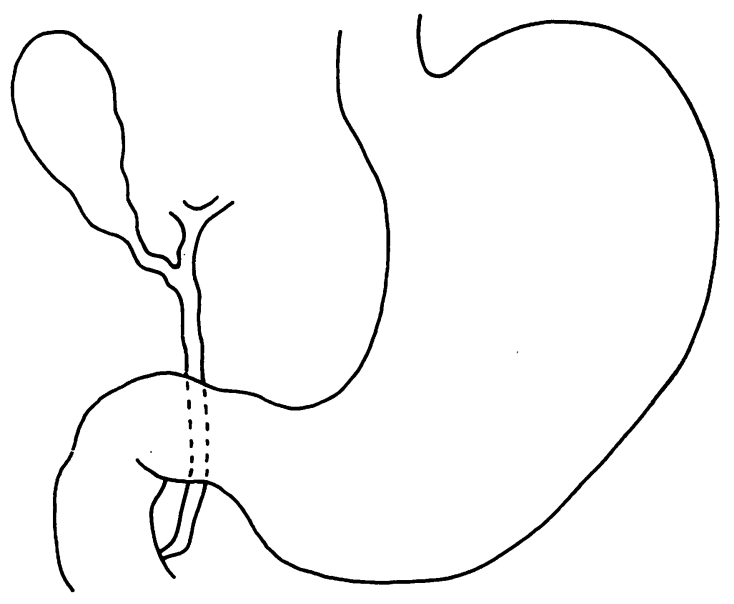

FIG. 3. Normal relationship of common bile duct and duodenum. 
of the first part of the duodenum and then distal to it to open into the second portion (Fig. 3). The extensive fibrosis and adhesions, particularly of the hepatogastric and hepatoduodenal ligaments, could easily alter the normal anatomical relationship and make it possible for an anteriorly placed ulcer which is superior to penetrate the common bile duct. The ulcer need not be situated in the postbulbar region to allow barium to enter the biliary ducts as was suggested by Barton and Cockshott (1961). In those cases where barium entered the bile ducts during screening it passed from the duodenal cap into the ducts (Fig. 1). In no case was barium seen to enter via the ampulla of Vater. In those cases in which air is seen in the ducts (Fig. 2), it is in the common bile duct above the apex of the duodenal cap and not in the distal portion.

The cholecystoduodenal type of fistula can also be produced by gall bladder disease because of its proximity to the duodenum as well as to other adjacent parts of the gut to form cholecystogastric or cholecystocolic fistulas. The acute cholecystitis in case 4 resulted in a cholecystogastric fistula forming.

These fistulas produce no peculiar symptoms of their own other than that of the casual peptic ulceration. It was therefore at a barium meal examination or on a plain abdominal film that all the cases were first discovered. However, in the case of the fistula resulting from gall bladder disease the history was very short and the symptoms were acute.

Although the course of the disease can be fatal, the prognosis in biliary fistula from penetrating chronic duodenal ulcer is generally considered good, the causal disease being the only factor to be dealt with. In the account of Hutchings et al (1956) there were cases in which subsequent radiographs showed that the choledochoduodenal fistulas were still present after one to three years of medical management. All of our cases except one had surgical treatment and no gall stones were seen in any of them. One case of ascending cholangitis has been reported (Köberle, 1938) and one of our cases also had this rare complication. In our case 3, with extensive fibrosis and a grossly dilated common bile duct, presumably with stasis, a superadded ascending infection did result forming an abscess under the liver.

\section{SUMMARY}

A review of 13 cases of biliary fistula in Nigerians is presented and contrasted with other reported series.
Over $90 \%$ of the cases resulted from a penetrating chronic ulcer to form choledochoduodenal fistulas.

Most of these cases of chronic duodenal ulcer had a long history and some of them had duodenal stenosis. There was only one case resulting from gall bladder disease, thus making the latter an uncommon cause of biliary fistula in Nigerians. The fistulas resulting from duodenal ulcer disease produce no specific symptoms other than those related to the ulcer. The diagnosis was radiological in all cases.

The rare complication of ascending cholangitis and liver abscess in one of the cases is described.

\section{REFERENCES}

Aitken, A. B. (1933). Remarks on peptic ulcer. W. Afr. med. J., 6, 63-65.

Antia, A. U., and Solanke, T. F. (1967). Pyloric obstruction complicating peptic ulceration in childhood. Ibid., 16, 86-88

Barton, C. J., and Cockshott, W. P. (1961). Post-bulbar duodenal ulceration in Nigeria. Brit. J. Radiol, 34, 216-220.

Cogbill, C. L., and Roth, H. P. (1953). Choledochoduodenal fistula. Report of 2 cases due to duodenal ulcers. Amer. Surg., 19, 480-488.

Craighead, C. C., and St. Raymond, A. H., Jr (1954). Duodenal fistula, with special reference to choledochoduodenal fistula complicating duodenal ulcer. Amer. J. Surg., 87, 523-533.

Dean, G. O. (1939). Internal biliary fistulas: a discussion of internal biliary fistulas based on 29 cases. Surgery, 5, 857-864.

Epperson, D. P., and Walters, W. (1953). Spontaneous internal biliary fistulas, Proc. Mayo Clin., 28, 353-360.

Ellis, M. (1948). A study of peptic ulceration in Nigeria. Brit. J. Surg., 36, 60-65.

Garland, L. H., and Brown, J. M. (1942). Roentgen diagnosis of spontaneous internal biliary fistulae, especially those involving the common duct. Radiology, 38, 154-159.

Hutchings, V. Z., Wheeler, J., and Puestow, C. B. (1956). Choledochoduodenal fistula complicating duodenal ulcer. Arch. Surg., 73, 598-605

Kehr, H. (1913). Cited by Borman, C. N., and Rigler, L. G. (1937). Spontaneous internal biliary fistula and gallstone obstruction. Surgery, 1, 349-378.

Köbcrle, F. (1938). Beitrag zur kenntris der auf ulcusbasis entstandenen inneren Gallenfisteln. Arch. klin. Chir., 192, 572-580. Cited by Jordon, P. H., Jr, and Stirrett, L. A. (1956). Treatment of spontaneous internal biliary fistula. Amer. J. Surg., 91, 307-313.

Konstam, P. G. (1959). Peptic ulcer in India. Indian J. med. Sci., 13, 489-492. Cited by Cleave, T. L. (1962). Peptic Ulcer, p. 44. Wright, Bristol.

Monaco, G., Brunetti, E., and Cocchieri, G. (1966). Considerazioni clinico-radiologiche in tema di fistole bilio-digestive da ulcera gastro-duodenale. Policlinico, Sez. chir., 73, 153-171.

Parnis, R. O. (1964). Gall bladder disease in Nigeria. Trans. roy. Soc. trop. Med. Hyg., 58, 437-440.

Pitman, R. G., and Davies, A. (1963). The clinical and radiological features of spontaneous internal biliary fistulae. Brit. J. Surg., 50, 414-425.

Rose, A. W. (1935). Fractional gastric analyses in natives of Nigeria. W. Afr. med. J., 8, 10-12.

Solanke, T. F., and Lewis, E. A. (1968). Unpublished material.

Stephenson, F. B. (1921). Opaque meal in liver ducts. J. Radiol., 2, 35-40. Cited by Hutchings, Wheeler, and Puestow (1956).

Waggoner, and Le Mone, D. V. (1949). Clinical and roentgen aspects of internal biliary fistulas. Radiology, 53, 31-41.

Weinberger, J., and Rosenthal, A. (1945). Choledochoduodenal fistula. Case report. Amer. J. Roentgenol., 53, 470-473. 